\title{
Pengembangan Ketrampilan dengan Pelatihan Memasak Aneka Hidangan Ikan Gurame kepada Kelompok Ekstra Kurikuler Tata Boga Siswa SMA Permai Pluit Jakarta
}

\author{
Nonot Yuliantoro \\ Dosen Fakultas Pariwisata Universitas Pelita Harapan, Email: nonot.yuliantoro@uph.edu
}

\author{
Histori Artikel \\ Submitted: \\ 24 April 2019 \\ Reviewed: \\ 27 April 2019 \\ Accepted: \\ 1 Mei 2019 \\ Published: \\ 15 Juni 2019
}

\begin{abstract}
Cooking is an art to process raw materials into ready to eat dish with a proper cooking methods. To be able to cook well and properly people needs training at the right way. Pelita Harapan School of Hospitality and Tourism carry out community service cooking training activities aimed to the cooking club at Permai Senior High School Pluit Jakarta. The purpose of this community service is to share cooking skill and knowledge to the member of cooking club at Permai High School Pluit Jakarta since they need assistance to improve their cooking and food presentation skill. Pre test was conducted before the training to find out the basic skill and knowledge of cooking especially gurame fish, the ending of community service activities was carried out the post test to determine the effectiveness of the gurame cooking training that had been done. Cooking training activities to the member of cooking class Permai High School Students has a positive influence because the cooking club member became more skillfull and understand in processing gurame into various Nusantara Recipes.
\end{abstract}

Keywords: Cooking training, gurame fish, pre test and post test

\section{Pendahuluan}

Memasak adalah seni mengolah bahan makanan yang belum layak makan menjadi hidangan yang menggugah selera, dan menarik dalam penyajiannya. Estetika menghidangkan makanan dalam industri hospitality adalah krusial dengan mengedepankan pemilihan bahan yang baik, rasa yang lezat dan penyajian diatas piring yang artistik dan menarik. Memasak merupakan salah satu kegiatan yang menyenangkan terutama untuk para siswa sekolah menengah atas, yang menjadikan memasak sebagai penyegaran atas kegiatan rutin disekolahnya.

Kompetensi dan pengetahuan yang memadai dalam memasak dapat diperoleh di lembaga pendidikan vokasi memasak. Lembaga pendidikan vokasi memasak memiliki peran penting dalam industri kuliner sebagai tempat pelatihan individu yang ingin mendapat pengetahuan tentang memasak dan kemudian dapat terjun di dunia usaha kuliner baik sebagai profesional juru masak maupun sebagai wirausahawan.

Salah satu masakan yang populer di indonesia adalah masakan yang berbahan dasar ikan gurame. Ikan gurame merupakan salah satu dari lima belas jenis komoditas ikan yang didorong pemerintah untuk peningkatan produksi dan pendapatan petani. Selain itu, ikan gurame termasuk dari dua belas jenis komoditas ikan yang dipilih pemerintah untuk pemenuhan gizi masyarakat. Gurame juga banyak digemari oleh masyarakat Indonesia karena memiliki rasa yang gurih dan lezat (Purpowardoyo dan Djarijah, 1994).

Salah satu kegiatan Tri Drama Perguruan tinggi adalah Pengabdian kepada Masyarakat (PKM). Hal ini tercantum dalam pasal 20 ayat 2 Undang-undang No.20 Tahun 2003 tentang 
Sistem Pendidikan Nasional yang secara tegas menyatakan bahwa perguruan tinggi berkewajiban menyelenggarakan penelitian dan pengabdian kepada masyarakat. Kegiatan pengabdian kepada masyarakat adalah kegiatan yang mencakup upaya peningkatan kualitas sumberdaya manusia antara lain dalam perluasan wawasan, pengetahuan dan peningkatan ketrampilan yang dilakukan untuk perwujudan dharma bakti. Kegiatan pengabdian kepada masyarakat merupakan wujud kepedulian untuk berperan aktif dalam meningkatkan kesejahteraan dan memperdayakan masyarakat luas.

Berdasarkan latar belakang tersebut, Fakultas Pariwisata Universitas Pelita Harapan mengembangkan program pelatihan memasak hidangan ikan gurame. Pelaksanaan pengabdian kepada masyarakat dalam bentuk pelatihan memasak ini diberikan kepada siswa Sekolah Menegah Atas Permai Pluit Jakarta, secara khusus ditujukan kepada kelompok siswa yang mengikuti kegiatan ekstra kurikuler tata boga. Kegiatan pengabdian kepada masyarakat yang berupa pelatihan ini bertujuan untuk (1) menambah wawasan dan meningkatkan ketrampilan memasak para siswa yang tergabung dalam kelompok ekstra kurikuler tata boga SMA Permai Pluit Jakarta, mengingat kegiatan ekstrakurikuler memasak yang dilakukan di Sekolah Menegah Atas Permai Pluit Jakarta diminati oleh banyak siswa. (2) memperkaya dan mendalami aneka menu hidangan ikan gurame yang ada di Nusantara. (3) membuka wawasan dalam etika penyajian hidangan ikan Gurame. Tujuan dari kegiatan pelatihan memasak ikan gurame dalam kegiatan pengabdian kepada masyarakat ini merespon terhadap kebutuhan akan penambahan wawasan memasak, baik secara ketrampilan dasar memasak maupun jenis menu yang dimasak dari kelompok ekstra kurikuler tata boga di sekolah Permai tersebut. Dengan dilaksanakannya pengabdian kepada masyarakat berupa kegiatan pelatihan memasak hidangan ikan gurame dengan berbagai macam menu Nusantara memberikan kontribusi akan kebutuhan pelatihan untuk para siswa di Sekolah Menengah Atas Permai Pluit Jakarta.

\section{Metode}

Pelaksanaan kegiatan pengabdian kepada masyarakat yang dilakukan dalam format pelatihan. Menurut Noe et al (2013) pelatihan dipandang sebagai jalan untuk menciptakan kemampuan intelektual yang meliputi ketrampilan dasar (basic skills), ketrampilan ahli (advanced skills) dan kemampuan memotivasi diri (self motivated creativity). Metode pelaksanaan kegiatan akan dilakukan dalam bentuk:

a) Metode presentasi

Metode dengan kondisi para peserta pelatihan menjadi penerima pasif dari informasiinformasi yang diberikan. Metode yang digunakan adalah metode ceramah (lecture), yaitu menyampaikan informasi kepada peserta pelatihan. Materi informasi berisi tentang cara memilih ikan segar, aneka resep nusantara dan standar kebersihan diri dan lingkungan dapur.

b) Metode hands on

Metode yang mengharuskan para peserta untuk lebih aktif dalammengikuti proses pelatihan. Metode ini menggunakan teknik on the job training (OTJ), yaitu teknik dengan kondisi peserta pelatihan terjun langsung dalam proses memasak ikan gurame yang telah diajarkan dalam metode ceramah. Setiap kelompok membuat empat hidangan ikan gurame.

c) Metode Membangun Kelompok

Metode yang dirancang untuk meningkatkan kerjasama dan efektifitas dalam suatu tim. Dalam pelaksanaan kegiatan digunakan teknik pelatihan kelompok. Tujuan dilakukan pengelompokan ini adalah untuk memudahkan instruktur dan fasilitator dalam mengajarkan dan mengawasi para peserta dalam mengikuti kegiatan pelatihan. 


\section{Pariwisata}

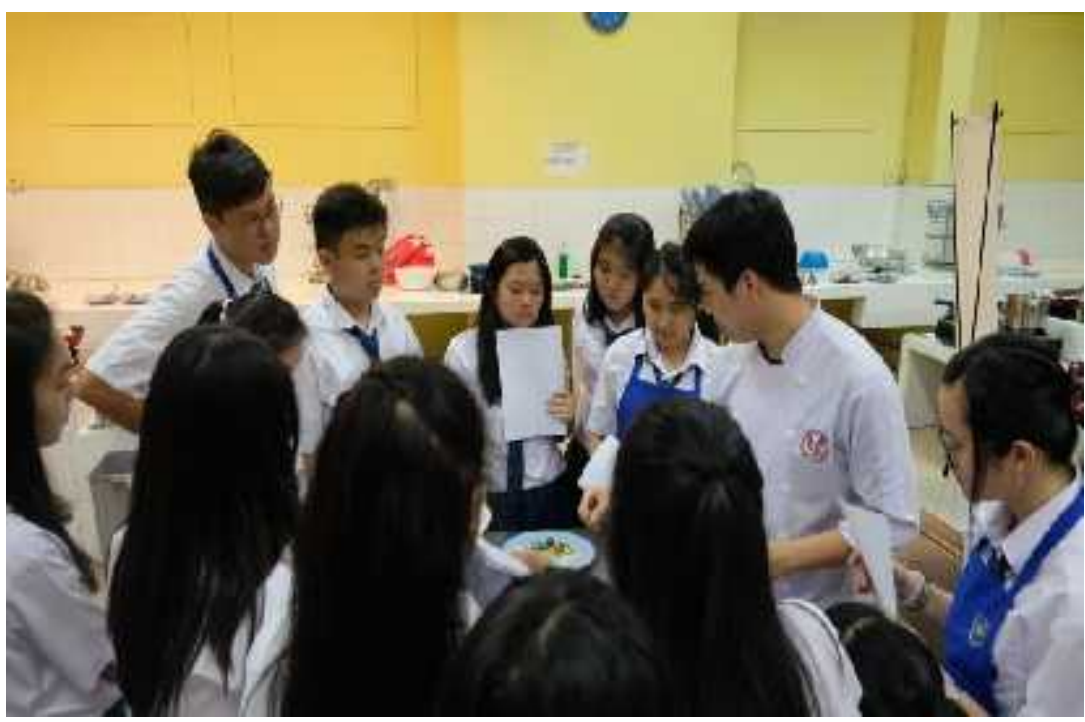

Gambar 1: Foto Pelatihan Praktik

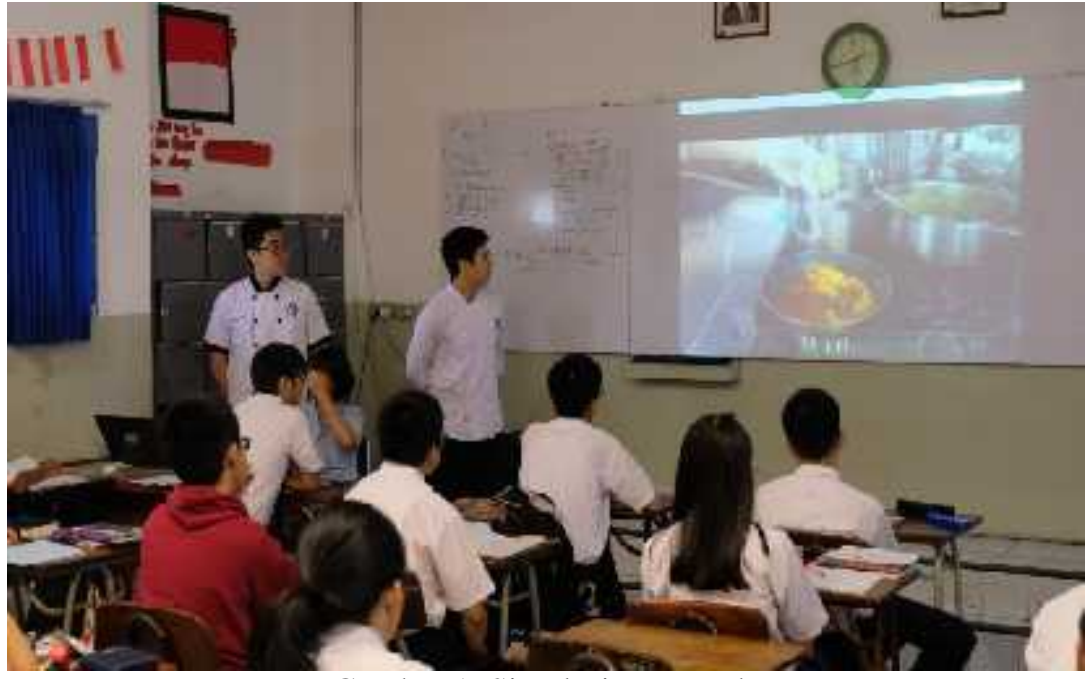

Gambar 1: Simulasi Memasak

Persiapan kegiatan pelatihan memasak hidangan ikan gurame ini dimulai dari minggu ke 2 bulan September 2018. Kegiatan yang pertama dilakukan adalah mengajukan proposal, setelah proposal disetujui, tim menghubungi bagian Hubungan Masyarakat SMA Permai Pluit Jakarta untuk kepastian tanggal pelaksanaan dan pengaturan jumlah peserta yang akan mengikuti pelatihan memasak hidangan ikan gurame serta persiapan teknis lainnya. Tim juga melaksanakan survey lokasi tempat dilaksanakannya kegiatan pada minggu pertama bulan Oktober 2018 serta mempersiapkan materi pelatihan memasak ikan gurame untuk para peserta pelatihan.

Pelaksanaan kegiatan pelatihan dimulai pada pukul 09.00 dan berakhir pada pukul 14.00. topik yang diajarkan dalam kegiatan pelatihan ialah pemahaman tentang ikan yang masih segar, kebersihan diri dan lingkungan dapur, cara menangani ikan gurame sebelum dimasak dan cara memasak ikan gurame masak bumbu pesmol, ikan gurame masak tauco, ikan gurame masak saus padang dan ikan gurame masak bumbu bali. 
Sebelum dilakukan kegiatan pelatihan, para peserta mengikuti tes awal yang berisi pertanyaan tentang cara memilih ikan segar, cara membersihakan ikan gurame, bumbu yang sering digunakan dalam masakan nusantara dan beberapa resep masakan ikan nusantara. Tim pelaksana terbagi dalam berbagai tugas antara lain sebagai instruktur, fasilitator, seksi konsumsi, seksi dokumentasi dan seksi perlengkapan. Dalam kegiatan pelatihan ini diawali dengan pembukaan dan dilanjutkan dengan pemutaran video seputar cara berpenampilan pada saat di area dapur, contoh ikan gurame yang masih segar, peralatan yang digunakan dan cara memasak ikan gurame. Selanjutnya semua peserta mencoba memasak ikan gurame dibimbing oleh instruktur yang bertugas. Di akhir program, tim pelaksana melakukan penilaian terhadap produk yang dibuat oleh peserta serta melakukan kembali tes akhir untuk mengetahui efektifitas pelatihan dengan melihat peningkatan pengetahuan tentang ikan gurame dan cara mengolahnya dengan berbagai resep nusantara

Tabel 1

Daftar Pertanyaan Tes

\begin{tabular}{cl}
\hline No & \multicolumn{1}{c}{ Daftar Pertanyaan } \\
\hline 1 & Sebutkan dua ciri ikan segar? \\
2 & Berat timbangan berapa ons biasanya ikan gurame dimasak? \\
3 & Bagaimana cara membersihkan sisik ikan Gurame? \\
4 & Bagaimana cara membersihkan isi perut ikan gurame? \\
5 & Bagaimana cara memyiangi ikan gurame sabelum dimasak? \\
6 & Jenis nutrisi apa yang terkandung pada ikan gurame? \\
7 & Apa yang disebut bumbu dapur? \\
8 & Apa bedanya ditumis dan digoreng? \\
9 & Dengan cara apa saja ikan gurame dimasak? \\
10 & Sebutkan jenis masakan ikan tradisional nusantara? \\
\hline
\end{tabular}

\section{Hasil dan Pembahasan}

Ikan masak pesmol adalah salah satu kekayaan kuliner nusantara, menu yang banyak dijumpai di daerah jawa barat ini dibuat dengan menggunakan ikan gurame sehingga memberi kesan yang istimewa. Dalam proses pembuatannya memerlukan ketrampilan untuk menggoreng ikan dengan benar dan memasak kuah pesmol yang otentik untuk dituang diatas ikan gurame goreng. Sedangkan ikan masak tauco adalah adaptasi bumbu dan jenis masakan peranakan yang sekarang memperkaya kasanah kuliner nusantara, seperti halnya ikan bumbu pesmol, ikan gurame masak tauco ini memerlukan ketrampilan untuk menggoreng ikan gurame dan ketrampilan membuat bumbu tauco yang akan disiramkan pada ikan gurame yang sudah digoreng. Untuk ikan gurami bumbu padang, selain memerlukan ketrampilan meggoreng ikan juga kemampuan untuk membuat bumbu padang yang sangat khas sehingga pada saat dipadukan dengan ikan gurame menjadi hidangan yang lezat dan berciri khas. Sedangka ikan bumbu bali memerlukan ketrampilan untuk membuat bumbu khas bali dengan menggunakan bumbu dapur khas nusantara untuk dicampurkan dan dimasak bersama dengan ikan gurame yag sudah goreng.

Melalui kegiatan pengabdian kepada masyarakat dalam bentuk pelatihan memasak ini, para siswa anggota ekstra kurikuler tata boga di SMA Permai Pluit Jakarta dapat mempelajari cara mejaga kebersihan diri dan lingkungan dapur, belajar tentang ikan yang segar dan cara untuk membersihakan dan menyianginya, membuat bumbu nusantara yang menggunakan bumbu dapur sebagai dasarnya, cara menggoreng ikan yang baik dan benar dan cara menumis bumbu agar menghasilkan cita rasa masakan yang mengundang selera. Semangat dan motivasi para siswa dalam mengikuti kegiatan pelatihan tercermin pada motivasi mereka yang mengikuti pelatihan dengan aktif dari awal acara hingga akhir dan kemampuan mereka dalam mengingat tentang materi yang diberikan selama kegiatan pelatihan berlangsung. Hal ini dapat dilihat dari 
hasil post test yang mengalami perubahan dibandingkan hasil pre test. Berikut adalah pemaparan dari hasil pencapaian pre test dan post test oleh para siswa selama mengikuti proses kegiatan pelatihan:

Tabel 2

Data pre test dan post test

\begin{tabular}{cccc}
\hline Subjek & Pre Test & Post Test & Gain $(\mathrm{d})$ \\
\hline 1 & 21 & 25 & 4 \\
2 & 21 & 24 & 3 \\
3 & 18 & 22 & 4 \\
4 & 16 & 20 & 4 \\
5 & 21 & 23 & 2 \\
6 & 25 & 30 & 5 \\
7 & 24 & 27 & 3 \\
8 & 25 & 27 & 2 \\
9 & 18 & 20 & 2 \\
10 & 18 & 21 & 3 \\
11 & 21 & 23 & 2 \\
12 & 21 & 22 & 1 \\
13 & 20 & 23 & 3 \\
14 & 17 & 19 & 2 \\
15 & 19 & 22 & 3 \\
16 & 19 & 20 & 1 \\
17 & 19 & 21 & 2 \\
18 & 19 & 23 & 4 \\
19 & 19 & 22 & 3 \\
20 & 19 & 24 & 5 \\
21 & 13 & 17 & 4 \\
22 & 24 & 25 & 1 \\
\hline \multicolumn{5}{r}{ Sumber: Data primer } & &
\end{tabular}

Hasil analisis statistik deskriptif tentang kegiatan pelatihan memasak hidangan ikan gurame sebelum pelatihan (pre-test)

Tabel 3

Hasil Uji Statistika pre test

\begin{tabular}{cc}
\hline $\begin{array}{c}\text { Memasak hidangan } \\
\text { Ikan Gurame }\end{array}$ & Hasil Pre-Test \\
\hline N & 22 \\
Mean & 19,8 \\
SD & 2,916 \\
\hline
\end{tabular}

Sumber: Data primer

Hasil analisis statistik deskriptif tentang kegiatan pelatihan memasak hidangan ikan gurame sesudah pelatihan (post-test) 
Tabel 4

Hasil Uji Statistika post test

\begin{tabular}{cc}
\hline Memasak hidangan Ikan & Hasil Post-Test \\
Gurame & 22 \\
N & 22,7 \\
Mean & 2,930 \\
SD &
\end{tabular}

Sumber: Data primer

Berdasarkan hasil pre-test dan post-test diketahui bahwa sebelum mendapatkan pelatihan, pemahaman awal siswa mengenai cara memasak ikan gurame masih rendah. Hal ini diketahui dari rata-rata pre-test yang cukup rendah yaitu 19,8. Setelah mendapatkan pelatihan, terjadi peningkatan rata-rata nilai pemahaman keterampilan memasak ikan gurame yaitu 22,7. Agar lebih meyakinkan, peningkatan ini juga diuji melalui uiji Wilcoxon, dan didapati bahwa peningkatan nilai siswa adalah meyakinkan. Tabel uji Wilcoxon dapat dilihat pada tabel berikut:

Table 5

Ranks

\begin{tabular}{llr|r|r}
\hline Ranks & & $\mathrm{N}$ & Mean Rank & Sum of Ranks \\
\hline \multirow{3}{*}{ Post Test - Pre Test } & Negative Ranks & $0^{\mathrm{a}}$ & .00 & .00 \\
\cline { 2 - 5 } & Positive Ranks & $22^{\mathrm{b}}$ & 11.50 & 253.00 \\
\cline { 2 - 5 } & Ties & $0^{\mathrm{c}}$ & & \\
\cline { 2 - 5 } & Total & 22 & & \\
\hline
\end{tabular}
a. Post Test $<$ Pre Test
b. Post Test $>$ Pre Test
c. Post Test $=$ Pre Test
Sumber: Data primer

Berdasarkan hasil uji Wilcoxon pada tabel 5, diperoleh hasil bahwa terdapat kenaikan yang meyakinkan dimana pemahaman siswa tentang memasak ikan gurame memperoleh kenaikan sebesar 22 (Positive Rank), yang berarti 22 siswa mengalami kenaikan dalam pencapaian skor post test dibandingkan skor pre test. Tidak ada seorang siswapun yang mengalami penurunan skor dari pre test ke post test 0 (Negative Ranks) dan juga tidak ada siwa yang mendapatkan nilai tetap 0 (Ties) dari skor pre test ke post test. Hasil tes statistik uji Wilcoxon dapat dilihat pada tabel berikut:

Table 6

Test Statistics ${ }^{\mathrm{a}}$

\begin{tabular}{lr}
\hline & Post Test - Pre Test \\
\hline$Z$ & $-4.133^{\mathrm{b}}$ \\
\hline Asymp. Sig. (2-tailed) & .000 \\
\hline
\end{tabular}

a. Wilcoxon Signed Ranks Test

b. Based on negative ranks.

Sumber: Data primer

Berdasarkan hasil tes statistik pada tabel 6, diketahui bahwa Asymtotic Significant pemahaman siswa tentang memasak ikan gurame adalah 0,000, dimana hasil tersebut dibawah 0,05 yang berarti bahwa pelatihan memasak ikan gurame dapat meningkatkan pemahaman memasak ikan gurame secara meyakinkan. Berdasarkan hasil tersebut dapat dikatakan bahwa pelatihan 
memasak ikan gurame mampu memberikan pemahaman yang baik kepada para siswa tentang keterampilan cara memasak yang benar secara umum dan cara mengolah hidangan Ikan Gurame dengan berbagai resep Nusantara. Pelaksanaan pelatihan dilakukan dengan membagi peserta dalam kelompok kecil dan didampingi oleh satu instruktur sehingga para siswa peserta pelatihan bisa maksimal dalam mencoba mempraktikan segala materi yang telah diberikan sebelum acara praktik memasak dimulai serta bisa leluasa bertanya kepada instruktur. Demikian pula para instruktur bisa lebih maksimal dalam mendampingi peserta menjalani pelatihan sesuai dengan program yang telah dicanangkan.

\section{Kesimpulan}

Setelah dilakukan penganalisaan tentang pelatihan memasak hidangan ikan gurame kepada kelompok ekstra kurikuler tata boga siswa SMA Permai Pluit Jakarta dapat disimpulkan bahwa pelatihan yang dilakukan oleh Fakultas Pariwisata, Universitas Pelita Harapan dalam rangka melaksanakan kegiatan pengabdian kepada masyarakat adalah tepat guna mengingat antusias dari peserta untuk belajar memasak cukup tinggi.

Hasil pembahasan menunjukkan bahwa peningkatan pelatihan memasak hidangan ikan gurame pada para siswa SMA Permai Pluit Jakarta melalui Pre Test dan Post Test memiliki pengaruh positif yang signifikan terbukti dengan $\mathrm{p}$ value yang lebih kecil dari $\alpha(0.05)$ yang artinya kegiatan pelatihan memasak ikan gurame untuk siswa SMA Pertmai Pluit Jakarta berhasil meningkatkan ketrampilan memasak ikan gurame secara meyakinkan. Hasil kegiatan pelatihan ini dapat digunakan sebagai bahan pertimbangan bagi Fakultas Pariwisata Pelita Harapan dalam melakukan kegiatan pengabdian kepada masyarakat periode mendatang untuk membuat program pelatihan yang lebih komprehensif sebagai bentuk tindak lanjut dari program yang telah dilakukan sehingga kelompok ekstra kurikuler tata boga di SMA Permai Pluit Jakarta bisa mendapatkan program pelatihan yang berkesinambungan.

\section{Ucapan Terima kasih.}

Kami mengucapkan terima kasih kepada pihak-pihak yang telah turut terlibat dalam penyelenggaraan PKM dengan kegiatan pelatihan memasak ikan gurame, khusunya kepada:

1. SMA PERMAI Pluit Jakarta yang telah memfasilitasi penyelenggaraan pengabdian kepada masyarakat dalam bentuk pelatihan memasak ikan gurame bagi para siswa anggota ekstra kurikuler tata boga.

2. LPPM UPH yang telah bersedia memfasilitasi terlaksananya pelatihan memasak ikan gurame ini.

3. Demikian pula ucapan terima kasih kepada mahasiswa Prodi Pengelolaan Perhotelan Fakultas Pariwisata Universitas Pelita Harapan yang terlibat dalam kegiatan PKM ini serta semua pihak yang telah membantu dalam penyelesaian artikel tentang Pengembangan Ketrampilan Dengan Pelatihan Memasak Aneka Hidangan Ikan Gurame Kepada Kelompok Ekstra Kurikuler Tata Boga Siswa SMA Permai Pluit Jakarta, semoga artikel ini berguna bagi yang membacanya.

Referensi:

Noe, R, Hollenbeck, J. dan Gerhart, B., Wright, P. (2013). Fundamental of Human Resource Management, 5ed. New York: McGraw-Hill.

Purpowardoyo, H., dan Djarijah, A.S. (1992). Membudidayakan Gurame. Kanisius. Yogyakarta.

Undang-undang Republik Indonesia Nomor 20 Tahun 2013 Tentang System Pendidikan Nasional. 


\section{Jurnal Abdimas}

\section{Pariwisata}

\section{LAMPIRAN}

\section{Dokumen Kegiatan}
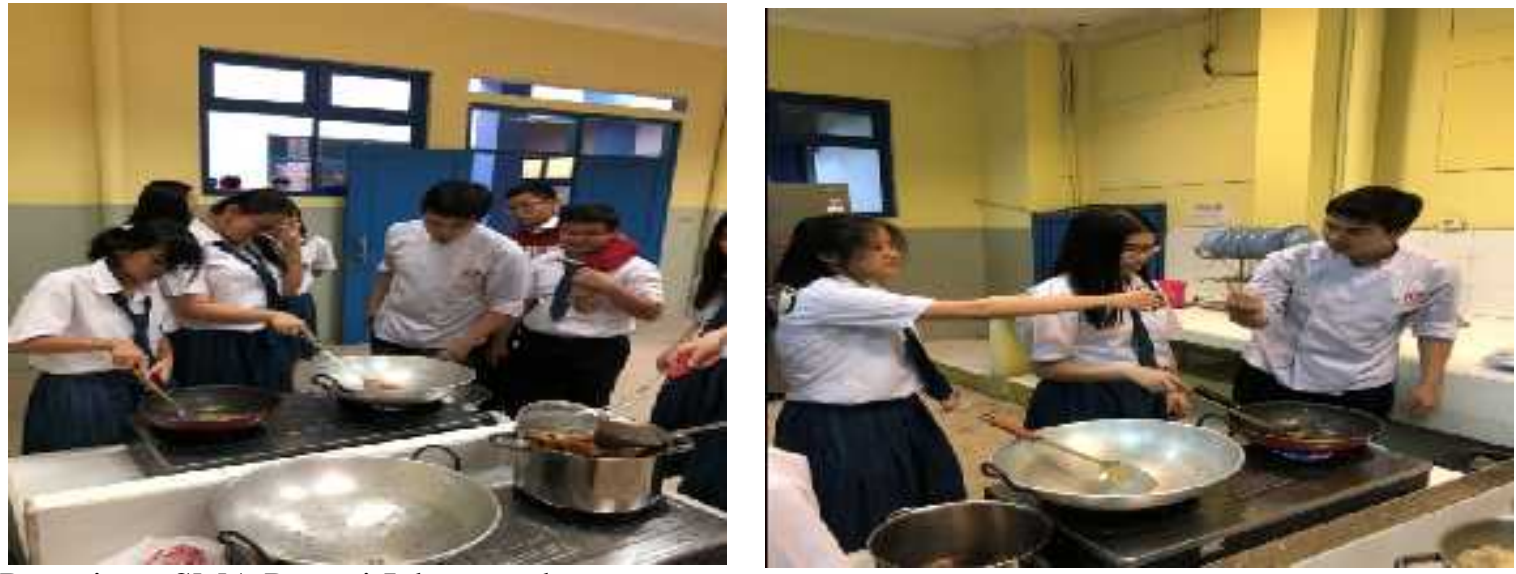

Para siswa SMA Permai Jakarta sedang memasak ikan gurame
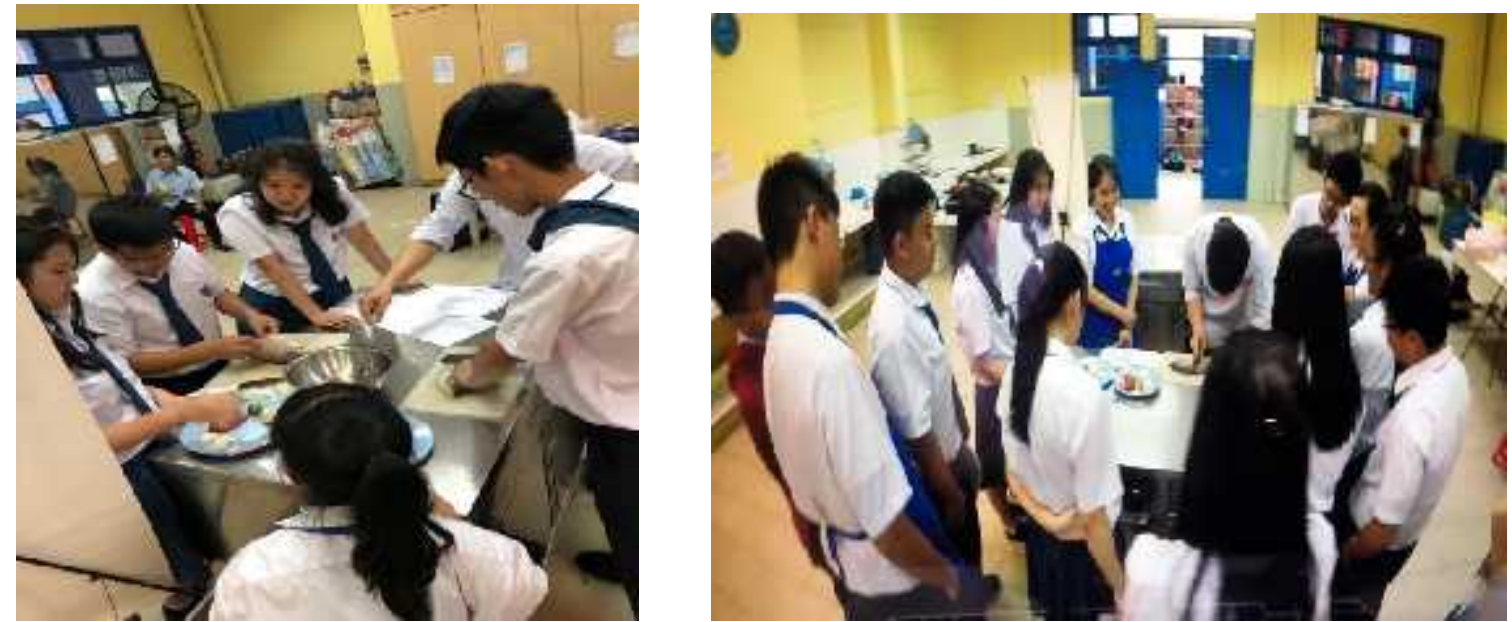

Tiap siswa berperan aktif dan antusias

mengikuti kegiatan pelatihan

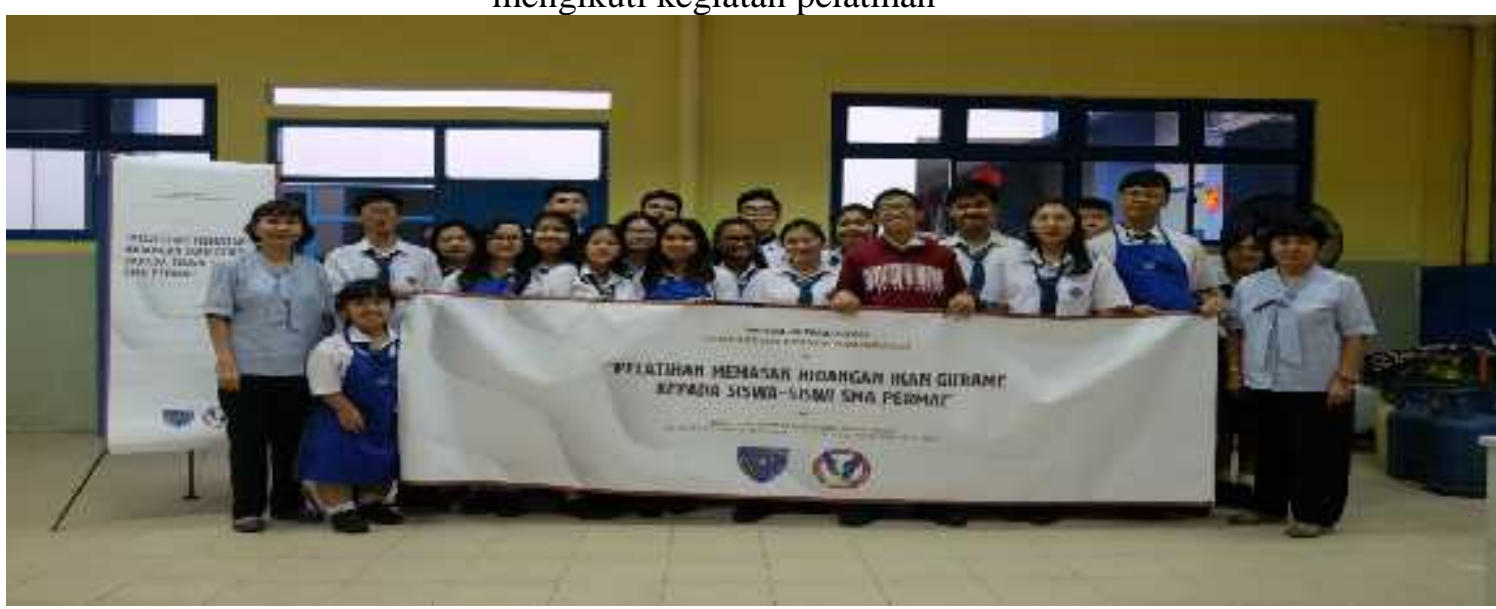

Foto bersama dengan guru dan para siswa SMA Permai Pluit Jakarta. 